\title{
Trans-femoral lower limb transplantation in a Sri Lankan patient: a case report and surgical technique
}

\author{
Joel Arudchelvam ${ }^{1}$, Amila Ratnayake ${ }^{1}$, Nuwan Wijesinghe ${ }^{1}$, Lewan Kariyawasam ${ }^{1}$, Premil \\ Rajakrishna ${ }^{1}$, Sadath Anver ${ }^{1}$
}

Ceylon Medical Journal 2018; 63: 35-36

DOI: http://doi.org/10.4038/cmj.v63i1.8624

\section{Introduction}

Lower limb transplantation is rarely done in the world [1]. Up to date only four such transplantations have been reported prior to this patient [1]. This report describes the first lower limb transplant done in Sri Lanka and the 5th in the world.

\section{Case report}

A 32 year old male underwent above knee amputation one year ago following an accidental vascular injury. He was mobilized using a prosthesis. He expressed willingness to undergo lower limb transplantation. Institutional ethical approval was obtained for the transplantation. A 52 year old male donor who became brain dead following spontaneous intra-cerebral haemorrhage became available on $24^{\text {th }}$ July 2017. Both the donor and the recipient were of Blood group O. Lymphocyte cross match was compatible and the cytomegalovirus status was donor +ve to recipient -ve. The length of limb was matching.

The donor's left lower limb and both kidneys were prepared for donation. A circumferential incision was made at mid-thigh level along a pre-marked line. This line was determined by measuring amputation stump length and donor thigh length. The limb vessels including great saphenous vein were dissected up to the level of the common iliac vessels. Common iliac artery was prepared for cannulation and cold perfusion of the limb (kidneys were cold perfused through the lower aorta through a separate cannula). Muscles were transected at the level of incision and sciatic nerve was mobilized up to the sciatic notch and was transected. Bone was divided about an inch inferior to the skin incision. The donor lower limb was left connected to the donor by only the iliac vessels at this stage until the recipient was prepared for transplantation.
Recipient was given basiliximab $40 \mathrm{mg}$, methyl prednisolone $1000 \mathrm{mg}$, tacrolimus $5 \mathrm{mg}$ and mycophenolate mofetil $1 \mathrm{~g}$ as pre-operative immuno-suppressants.

Recipient's amputation flaps were opened and the lower end of the femur was dissected free of fibrous tissue and the bone end was trimmed. Recipient's superficial femoral vessels were prepared for anastomosis through a separate incision at the groin. Sciatic nerve was identified and mobilized and the neuroma found at the end was trimmed.

At this stage donor lower limb was perfused with 10 liters of cold histidine tryptophan ketoglutarate (HTK) solution through the common iliac artery. The limb was packed with ice during cold perfusion. Then the iliac vessels were divided and the limb was separated from the donor for transplantation.

The femoral bones of the donor and recipient were trimmed at the appropriate levels after matching the height and knee joint level. Femoral plating was done with a 10 hole dynamic compression plate. The donor limb was perfused with 3 units of warm Hartmann solution and the ice pack was removed before starting vascular anastomosis. The recipient was given $250 \mathrm{ml}$ of $20 \%$ mannitol to minimize the reperfusion effects. The recipient was given 5000 IU of heparin before clamping the vessels. The vascular anastomoses were done next in an end-to-side fashion using 5/0 polypropylene suture for veins and 6/0 polypropylene suture for the artery. The limb was then re-perfused. Immediately distal pulse was achieved. The first $300 \mathrm{ml}$ of blood was let out to reduce the entry of metabolites into the systemic circulation. There were no significant reperfusion effects. The sciatic nerve was anastomosed next with 8/0 polypropylene epineural sutures, muscles were sutured with 1 polyglactin interrupted simple sutures. Fasciotomy was not done.

\section{${ }^{1}$ Teaching Hospital Anuradhapura, Sri Lanka.}

Correspondence: JA, e-mail: <joelaru@yahoo.com>. Received 26 January 2018 and revised version accepted 14 February 2018

This is an open-access article distributed under the terms of the Creative Commons Attribution License, which permits unrestricted use, distribution, and reproduction in any medium, provided the original author and source are credited. 
Patient was sent to the intensive care unit for postoperative monitoring. He was kept on heparin 1000 IU hourly infusions until post-operative day 3 and it was then converted to low molecular weight heparin subcutaneous injections. Methyl prednisolone $250 \mathrm{mg}$ IV was given from day1 to day 3 and methyl prednisolone $125 \mathrm{mg}$ IV was given on days 4 and 5 . We planned to continue IV methyl prednisolone for 14 days and then convert to oral prednisolone 30mg daily for one month, 20 $\mathrm{mg}$ in the second month and $10 \mathrm{mg}$ in the third month, reduced to $5 \mathrm{mg}$ in the fourth month and then stop. Tacrolimus was continued at $3 \mathrm{mg}$ oral twice daily and mycophenolate mofetil $1 \mathrm{~g}$ twice daily. We aimed to maintain tacrolimus levels at 12 to 17 . Patient was also started on cytomegalovirus prophylaxis with valgancyclovir.

On post-operative day one the patient developed limb swelling and increased intra-compartmental pressure on leg and thigh (28 centimeters of water). A lateral single incision fasciotomy was done on the leg and a lateral incision fasciotomy was done on the thigh extending from donor to recipient thigh. At fasciotomy, the leg muscles were noted to have contraction with diathermy stimulation. NPWD were applied to wounds. Duplex ultrasound done on days 1, 2 and 4 showed patent vessels. Muscle biopsy from the lateral compartment of the leg taken on day one showed features suggestive of ischaemia related injury. Until this time the patient did not develop any further complications.

At present 6 months after the transplant, the patient can move his knee joint and partially bear weight. He has positive Tinel's sign up to ankle joint and the patient reports burning sensation at the ankle joint level which are early signs of sensory recovery.

\section{Discussion}

Lower limb transplant is rarely done in the world and only five such transplantations have been done with the latest being our patient [1].

Zuker et al. performed the first lower limb transplantation in 2006 [2]. The lower limb from the sacrificed conjoined (ischiopagus) twin was transplanted to the surviving twin. At six years of follow up the patient walks with braces and has intact but reduced sensation. Cavadas et al. performed bilateral trans femoral lower limb transplantations [3]. This is the first lower limb allotransplantation. At one year patient was ambulant with partial weight bearing. At two years, limbs were amputated due to development of cerebral lymphoma. Ozkan et al. performed the first triple limb transplantation (bilateral upper limbs and right lower limb) on a 32 year old man in Turkey in 2012 [4]. Patient lost the lower limb on day one due to "rejection". He died five months after surgery due to complications secondary to infection. Erdem et al. first attempted quadruple extremity transplantation on a 27 year old man who lost his limbs due to electrocution. The patient developed cardiac arrest intra-operatively due to metabolic derangement [5]. He died on post-operative day five.

In the first case described by Zuker et al immunosuppression was not used because the graft was an isograft (from the twin) [2]. In the second case described by Cavadas et al even though the patient was able to mobilise with partial weight bearing, the limb had to be amputated because the patient developed a complication due to long term immuno-suppression (lymphoma) [3]. In the fourth case described by Erdem et al. it appears that due to practical problems of performing all 4 limb transplants together, it was difficult to maintain the metabolic balance of the patient during surgery which resulted in his death [5].

Other than the first case all the other cases resulted in poor outcome. Lower limb amputees mobilise well with prosthesis and therefore do not want to undergo lower limb transplant. In addition there are risks involved with lifelong immunosuppression. Due to these reasons lower limb transplants are rarely carried out in the world. But transplantation results in the patient having a natural limb which moves, is with the patient all the time, self-heals and aesthetically looks better than a prosthesis. These aspects were explained to the patient and he was willing to have a new limb. Considering the early success with this procedure and because the patient is happy to have a new limb, we believe that lower limb transplantation can be offered to willing patients in the future.

\section{Conflicts of interest}

There are no conflicts of interest.

\section{References}

1. Edward W Swanson, Hsu-Tang Cheng, et al. Lower Extremity Allotransplantation: Are We Ready for Prime Time? Vascularized Composite Allotransplantation 2015; 2(2): 37-46.

2. Fattah A, Cypel T, Donner EJ, Wang F, Alman BA, Zuker RM. The first successful lower extremity transplantation: 6-year follow-up and implications for cortical plasticity. Am J Transplant 2011; 11: 2762-7.

3. Cavadas PC, Thione A, Carballeira A, Blanes M. Bilateral transfemoral lower extremity transplantation: result at 1 year. Am J Transplant 2013; 13: 1343-9.

4. Shores JT, Lee WP, Brandacher G. Discussion: Lessons learned from simultaneous face and bilateral hand allotransplantation. Plast Reconstr Surg 2013; 132: 433-4.

5. Nasir S, Kilic YA, Karaaltin MV, Erdem Y. Lessons learned from the first quadruple extremity transplantation in the world. Ann Plast Surg 2014; 73: 336-40. 